\title{
TÉTANO NO CLIMATÉRIO
}

\author{
Maurício Paulo Angelo Mieli*, José Mendes Aldrighi
}

Trabalho realizado na Faculdade de Saúde Pública da Universidade de São Paulo e no Hospital Universitário da Universidade de São Paulo, São Paulo, SP

\author{
*Correspondência: \\ Rua Comendador Miguel \\ Calfat, 128, Conjunto \\ 1401, Vila Olímpia \\ São Paulo, SP \\ Cep: $04537-080$ \\ Tel. (11) 3045-2420 \\ mieli@usp.br
}

\begin{abstract}
RESUMO
Oвjetivo. O presente estudo tem o propósito de avaliar mulheres brasileiras, acometidas pelo tétano e que estão no período do climatério.

Métodos. Os dados foram coletados a partir das publicações do DATASUS/Ministério da Saúde referentes às internações hospitalares (SIH) em hospitais do Sistema Único de Saúde (SUS) ou com ele conveniados. Os números sobre vacinações foram obtidos no Programa Nacional de Imunizações. Dados da população foram adquiridos junto ao Instituto Brasileiro de Geografia e Estatística (IBGE).

Resultados. Entre janeiro de 2001 e julho de 2004, enquanto que para o sexo masculino, com o aumento dos decênios, houve redução no total de internações devidas ao tétano, para o feminino aumentou. A frequiência com que ocorre a doença para ambos os sexos, de 35 a 64 anos, nas diferentes regiôes do Brasil, revelou que o Nordeste, seguido pelo Sudeste e Sul, foi a região mais atingida pela doença. Dados do ano 2002 mostraram que, entre 50 e 59 anos, apenas 15,73\% das pessoas foram devidamente protegidas contra o tétano.
\end{abstract}

Conclusão. A vida saudável na fase adulta depende de políticas públicas de saúde, no sentido de prevenir, adequadamente, a doença. No caso do tétano, a vacinação representa prevenção eficaz.

UNITERMOS: Climatério. Tétano.

\section{INTRODUÇÃO}

A idéia errônea de muitos adultos sobre vacinação, de que somente estaria indicada para recém-nascidos e crianças, tem que ser modificada por meio de campanhas esclarecedoras. No Brasil, a vacinação na vida adulta tem seu valor como prevenção rotineira, além de corrigir eventuais falhas de esquemas vacinais.

Vacinas contra gripe, antipneumocócica, antitetânica, além daquelas contra difteria, hepatite A e B, sarampo, parotidite, rubéola, varicela-zozter e meningocócica fazem parte de programas da imunização para adultos.

Nos Estados Unidos, o programa Immunization Action Coalization se propõe a vacinar adultos, utilizando o slogan "você nunca estará demasiado idoso para ser vacinado" !

A vacinação contra tétano deverá ser feita até os cinco anos de idade, com três doses da vacina tríplice; após, indica-se o reforço com toxóide tetânico, a cada dez anos.

A bactéria Clostridium tetani, agente causadora da moléstia, não sobrevive na presença de oxigênio; encontra-se sob a forma esporulada em locais como terra, areia, espinhos de plantas, fezes, agulhas de injeções não esterilizadas, poeira de rua, assim como nas pontas de metais enferrujados?

No organismo humano, a Clostridium tetanigermina, assume forma vegetativa e produz a tetanospasmina, toxina que ataca o sistema nervoso central e causa rigidez muscular em diversas regiões do corpo. O trismo, riso sardônico, dores nas costas, rigidez abdominal e da nuca, espasmos e convulsões estão entre os principais sintomas observados; o quadro pode complicar-se com parada cardiorrespiratória.
Para evitar a morte, impõe-se a terapêutica já na primeira semana; o tratamento inclui sedativos, relaxantes musculares, antibióticos e soro antitetânico. A partir de então, continua-se a administrar os medicamentos e aguarda-se a recuperação orgânica dos tecidos comprometidos, sobretudo o nervoso ${ }^{2}$.

O presente estudo tem o propósito de avaliar mulheres brasileiras, acometidas pelo tétano e que estão no período do climatério.

\section{Métodos}

O período do climatério foi o proposto por Notelovitz, que se estende dos 35 aos 64 anos $^{3}$.

Os dados sobre tétano foram coletados a partir das publicações do DATASUS/Ministério da Saúde referentes às internações hospitalares (SIH) em hospitais do Sistema Único de Saúde (SUS) ou com ele conveniados. Os números sobre vacinações contra tétano foram obtidos no Programa Nacional de Imunizações. Os dados da população foram adquiridos junto ao Instituto Brasileiro de Geografia e Estatística (IBGE).

\section{Resultados}

Em 2004, a população brasileira masculina e feminina, no grupo etário de 30 a 69 anos, em que se inclui o período do climatério, está apresentada pela Tabela I.

A Tabela 2 mostra o aumento progressivo da população feminina brasileira, no período de $200 \mathrm{I}$ a 2004.

As internações motivadas por tétano, nas faixas etárias entre 35 e 64 anos, divididas por sexo, no período de janeiro de 2001 a julho de 2004, estão demonstradas na Tabela 3. 


\begin{tabular}{|c|c|c|c|}
\hline Faixa etária & Homens & Mulheres & Total \\
\hline 30 a 39 anos & $\overline{6.288 .637}$ & $\overline{6.656 .817}$ & 12.945 .454 \\
\hline 40 a 49 anos & 9.842 .620 & 10.470 .950 & 20.313 .570 \\
\hline 50 a 59 anos & 6.309 .080 & 6.833 .481 & $|3| 42.56 \mid$. \\
\hline 60 a 69 anos & 2.257 .417 & 2.565 .013 & 4.822 .430 \\
\hline Total & 24.697 .754 & 26.526 .261 & 51.224 .015 \\
\hline
\end{tabular}

Fonte: Instituto Brasileiro de Geografia e Estatística (BGGE) - Ministério da Saúde/Secretaria da Saúde/ Datasus (MS/SE/Datasus)

Tabela 2 - Variação da população feminina de 30 a 69 anos, de $200 \mathrm{I}$ a 2004

\begin{tabular}{|c|c|c|c|c|}
\hline$\frac{\text { Faixa etária }}{30 \text { a } 39 \text { anos }}$ & $\frac{2001}{6.403 .031}$ & $\frac{\mathbf{2 0 0 2}}{6.487 .992}$ & $\frac{2003}{6.572 .580}$ & $\frac{2004}{6.656 .817}$ \\
\hline $\begin{array}{l}40 \text { a } 49 \text { anos } \\
50 \text { a } 59 \text { anos } \\
60 \text { a } 69 \text { anos } \\
\text { Total }\end{array}$ & $\begin{array}{c}10.083 .596 \\
6.596 .534 \\
2.479 .960 \\
25.563 .121\end{array}$ & $\begin{array}{c}10.213 .468 \\
6.676 .278 \\
2.508 .645 \\
25.886 .383\end{array}$ & $\begin{array}{c}\mid 0.342 .488 \\
6.755 .09 \mid \\
2.536 .934 \\
26.207 .093\end{array}$ & $\begin{array}{c}10.470 .950 \\
6.833 .481 \\
2.565 .013 \\
26.526 .261\end{array}$ \\
\hline
\end{tabular}

Fonte: Instituto Brasileiro de Geografia e Estatística (IBGE) - Ministério da Saúde/Secretaria da Saúde/ Datasus (MS/SE/Datasus)

\begin{tabular}{|c|c|c|c|}
\hline Faixa etária & Homens & Mulheres & Total \\
\hline$\overline{35 \text { a } 44 \text { anos }}$ & 274 & 33 & 307 \\
\hline 45 a 54 anos & 269 & 62 & 331 \\
\hline 55 a 64 anos & 186 & 71 & 257 \\
\hline
\end{tabular}

Fonte: Ministério da Saúde/Internações Hospitalares/Serviço Único de Saúde (SIH/SUS) $)^{5}$

Tabela 4 - Ocorrência do tétano segundo regiões do Brasil no período de janeiro de $200 \mathrm{I}$ a julho de 2004 para ambos os sexos

\begin{tabular}{llllllll}
\hline Tétano & $\frac{\text { Norte }}{35 \mathrm{a} 64 \text { anos }}$ & $\frac{\text { Nordeste }}{97}$ & $\frac{\text { Sudeste }}{372}$ & $\frac{\text { Sul }}{178}$ & $\frac{\text { C. Oeste }}{177}$ & $\frac{\text { Total }}{71}$ & $\frac{895}{89}$ \\
\hline
\end{tabular}

Fonte: Ministério da Saúde/Internações Hospitalares/Serviço Único de Saúde (SIH/SUS)

Tabela 5 - Doses aplicadas em 2001 e 2002 de DTP (dose tríplice bacteriana), dT (dose dupla adulto), toxóide tetânico, imunoglobulina humana antitetânica

\begin{tabular}{llll}
\hline Faixa etária & $\frac{\mathbf{2 0 0 1}}{50 \text { a } 59 \text { anos }}$ & $\frac{\mathbf{2 0 0 2}}{1.026 .361}$ & $\frac{\text { Total }}{2.019 .869}$ \\
\hline \hline
\end{tabular}

Fonte: Programa Nacional de Imunizações ${ }^{6}$

\section{Tabela 6 - Doses aplicadas em 2001 e 2002 de DTP (dose tríplice bacteriana), dT (dose dupla adulto), toxóide tetânico, imunoglobulina humana antitetânica, por regiões do Brasil}

\begin{tabular}{lllllll}
$\frac{F a i x a}{50 \text { a } 59 \text { anos ária }}$ & $\frac{\text { Norte }}{180.169}$ & $\frac{\text { Nordeste }}{533.008}$ & $\frac{\text { Sudeste }}{830.275}$ & $\frac{\text { Sul }}{339.940}$ & $\frac{\text { C. Oeste }}{136.477}$ & $\frac{\text { Total }}{2.019 .869}$ \\
\hline
\end{tabular}

Fonte: Programa Nacional de Imunizações ${ }^{6}$
A ocorrência do tétano de janeiro de 200 I a julho de 2004, nas regiões do Brasil, para ambos os sexos, é demonstrada na Tabela 4.

Na Tabela 5, estão demonstradas as imunizações DTP (dose tríplice bacteriana), dT (dose dupla adulto), toxóide tetânico, imunoglobulina humana antitetânica para ambos os sexos, em $200 \mathrm{I}$ e 2002. Pretendiase estudar comparativamente as faixas etárias de 35 a 64 anos; todavia, somente dados para a categoria 50 a 59 anos foram encontrados.

A Tabela 6 caracteriza por regiões do Brasil, ambos os sexos, em 2001 e 2002, as imunizações com DTP (dose tríplice bacteriana), dT (dose dupla adulto), toxóide tetânico, imunoglobulina humana antitetânica. Novamente, para faixas etárias de 35 a 64 anos somente foram encontrados dados pertinentes ao período de 50 a 59 anos.

\section{Discussão}

Um estudo de projeção sobre dados populacionais do Brasil, realizado pelo IBGE, mostrou que em 2000 a idade mediana elevouse para 25,3 anos e deve atingir 40 anos em 2050. Isto significa que hoje, ainda, o Brasil pode ser chamado de um país dos jovens; todavia, daqui a 50 anos será considerado nação de adultos e idosos? ${ }^{7}$.

As tabelas descortinam a real e atual situação das imunizações contra o tétano e a própria doença no Brasil, entre 35 a 64 anos.

A Tabela I mostra o crescimento populacional dos decênios estudados. Conforme projeção do IBGE, o país teve aumento de mais de 10 milhões de habitantes, chegando ao total de 181,6 milhões de pessoas em 2004. O contingente de idosos aumentará a tal ponto que, em 2050, haverá mais pessoas com 60 anos que com menos de $20^{7}$.

Em 1980, o número de mulheres a mais na população brasileira era de 753 mil. Em 2050, essa diferença deverá chegar a 6,2 milhões. A explicação para esse fato está nas altas taxas de mortalidade no sexo masculino com ênfase nas causas externas - como homicídios e acidentes de trânsito - encontradas entre jovens? ${ }^{7}$.

A Tabela 2 mostrou que, apesar do crescimento da população feminina ocorrer em todas as faixas etárias, poderá haver desequilíbrio no futuro: o aumento do número de mulheres com mais idade.

A Tabela 3 revelou as internações de homens e mulheres com 35 a 64 anos, entre janeiro de $200 \mathrm{I}$ e julho de 2004. Enquanto que para o sexo masculino, com o aumento dos decênios, houve redução no total de internações devidas ao tétano, para o feminino aumentou. A falta de conscientização ou de programas adequados para vacinação dos adultos pode ter contribuído para isto, uma vez que a vacina é altamente eficaz; contudo, exposição a causas externas é fator a ser analisado, para se implementar medidas de prevenção.

$\mathrm{Na}$ Tabela 4, avaliou-se a freqüência com que ocorre o tétano, para ambos os sexos, de 35 a 64 anos, nas diferentes regiões do Brasil. 0 Nordeste, seguido pelo Sudeste e Sul, foi a região mais atingida pela doença. Afora o fator de concentração populacional, provavelmente está envolvido o tipo de trabalho que esta população realiza. A bactéria causadora da doença pode ser encontrada na forma esporulada, em locais como terra, areia, espinhos de plantas; bem como em fezes, agulhas de injeções não esterilizadas, poeira e pontas de metais enferrujados.

Para analisar a Tabela 5, é importante nos reportarmos à Tabela I. Observou-se que de 12.837.326 de pessoas que tinham entre 50 e 59 
anos em 2002, apenas 2.019 .869 foram vacinadas. Isto equivale a apenas $15,73 \%$ de pessoas protegidas. Se considerarmos que não foram encontrados dados referentes ao restante das idades que integram a faixa etária proposta por Notelovitz, ou seja, de 35 a 65 anos, esta porcentagem se reduz ainda mais.

Curiosamente, a Tabela 6 revela ter havido um maior esforço para vacinação contra tétano nas três regiões mais afetadas pela doença, conforme a Tabela 4. Claro está que, se levarmos em consideração os números mostrados pelas Tabelas I, 4, 5 e 6, há que se implantar, urgentemente, programa de vacinação que possa proteger adultos desta doença.

O estudo das estimativas populacionais é importante recurso para adequar políticas públicas a novos perfis demográficos e suas repercussões à saúde.

Na vida adulta, muitos agravos à saúde decorreram da ausência de prevenção adequada na infância e adolescência. Contudo, o descuido na prevenção do adulto pode resultar em catástrofes e ressurgimento de algumas doenças graves, como tétano.

Desvios deverão ser corrigidos oportunamente, instituindo-se medidas eficazes. Infelizmente, estas acabam por ser realizadas em situações emergenciais, como rotinas de pronto-socorro.

A vida saudável na fase adulta depende de políticas públicas de saúde, no sentido de prevenir, adequadamente, doenças. No caso do tétano, a vacinação representa prevenção eficaz.

\section{ConClusão}

As bases para uma vida adulta saudável são estabelecidas já nas primeiras etapas da infância. Ao se pensar na prevenção, será necessária elaboração de roteiro de vacinação que a pessoa deverá seguir até sua velhice.

\section{Conflito de interesse: não há}

\section{SUMMARY}

\section{Tetanus IN the climacterium}

OBJECTNE. The purpose of this study was to evaluate Brazilian women in the climacterium who are affected by tetanus.

METHODS. Data were collected from publications of DATASUS/Ministério da Saúde (Health Ministry) referring to hospital admissions (SIH) in hospitals of the Sistema Único de Saúde (SUS) (Official Health System) and accorded hospitals. The numbers of vaccinations administered were obtained at the National Program of immunizations. Data regarding the population was obtained at the Brazilian Geography and Statistics Institute (IBGE).

RESULTS. Between January 200 I and July 2004, while for the male gender, with the passing of years there was reduction in the total number of admissions due to tetanus, for the female gender there was an increase. Frequency of the disease, for both genders aged from 35 to 64 years in the different regions of Brazil, disclosed that the there is a higher incidence in the Northeast, followed by the Southeast and South. Data for the year 2002 showed that in the age bracket from 50 to 59 years, only 15.73\% of the people were adequately protected against tetanus.

CONCLUSIONs. In the adultphase, healthy life depends on public health policies, in the sense of supplying appropriate prevention against the disease. In the case of tetanus, vaccination is an effective prevention. [Rev Assoc Med Bras 2006; 52(4): 229-3I]

KEY wORDS: Climacteric. Tetanus.

\section{REFERÊNCIAS}

I. Immunization action coalition [online]. Disponível em: http:// www.immunize.org. Acesso em: 25 set 2004.

2. Ferreira P. Tétano [online]. Disponível em: http://www.fiocruz.br/ glossario/tetano.htm. Acesso em: 27 set 2004.

3. Notelovitz M. Climateric medicine and science: a societal need. In: Notelovitz M, editor. The climateric in perspective. Lancaster: M.T.P. Press; 1988. p.19-21.

4. IBGE. Censos demográficos e contagem populacional e MS/SE/Datasus, a partir de totais populacionais fornecidos pelo IBGE, para os anos intercensitários [online]. Disponível em: http://tabnet.datasus.gov.br/ tabnet/tabnet.htm. Acesso: 25 set 2004

5. Ministério da Saúde. Sistema de Informações Hospitalares do SUS $(\mathrm{SIH} /$ SUS) [online]. Disponível em: http://tabnet.datasus.gov.br/tabnet/ tabnet.htm. Acesso em: 25 set 2004.

6. Programa Nacional de Imunizações [online]. Disponível em: http:// tabnet.datasus.gov.br/tabnet/tabnet.htm. Acesso em: 25 set 2004.

7. Gois A. País terá em 2050 indicador do Japão atual. Folha de São Paulo, São Paulo, 31 ago, 2004. p.C-I.

Artigo recebido: 02/03/05

Aceito para publicação: | 4//2/05 